\title{
The Chromosomes of Chironja
}

\author{
Niilo Virlilii
}

\section{INTRODUCTION}

Chironja is a new Citrus variety discovered in 1956 by Moscoso $(3)^{2}$ and introduced for cultivation by this Station. The original trees, found in the central highlands of Puerto Rico, have apparently grown from seed. The characteristics of the tree and its fruit are between those of grapefruit and orange, and it is supposed that the trees have resulted from natural crosses between them. Chironja is formed from the Spanish names "china"-orange, Citrus sinensis, and "toronja"-grapefruit, Cilrus paradisi.

Polyploidy, so common a means of evolution in the plant kingdom, has played little role in the evolution within the genus Citrus. Most species have diploid chromosome numbers, e.g. $2 \mathrm{n}-18(1,2)$. This is true also of the cultivated forms. Polyploidy tends to lower the quality of the fruit $(2,5)$. Thus it is apparent that selection for good fruit favors diploidy in cultivated strains. Even in the orange and grapefruit, where polyploids do occur, diploidy is to be expected in wide range.

The Cilus chromosomes are short; their size differences are slight. They are poor subjects for studying the fine chromosomal structure. In spite of this, structural rearrangements have been found, and they are regarded as the main means of evolution in the genus $(4,5)$.

In these circumstances we cannot expect much from a cytological checkup for understanding the origin of chironja. If the parent trees had been of different ploidy, we could apparently recognize the hybrid character of the chromosome complement. If there had been structural differences between the chromosomes of the parents, a careful analysis of the structure and meiotic behavior of the chironja chromosomes would probably reveal that hybridization occurred. Unfortunately the parent trees are unknown. However, the basic genetic mechanism of a valuable variety like chironja, which undoubtedly will be much propagated and used for further breeding, deserves to be known. A study of the PMC divisions of chironja was therefore undertaken, with the slight hope in mind that some hints on its descent could be obtained at the same time.

\section{MATERIALS AND METIODS}

A small sample of chironja flowerbuds was fixed in September 20, 1962, in the private garden of Mr. Carlos G. Moscoso in the Urbanización Santa

1 Associate Cytogeneticist, Agricultural Experiment Station, University of Puerto Rico, Río Piedras, P.R.

2 Italie numbers in parentheses refer to Jiterature Cited, p. 16. 
Marial, Río l'iedras. The material remained in the fixative (Carnoy 6:3:1) at $+1^{\circ} \mathrm{C}$. until preparation could be continued 6 months later. An overnight staining at $25^{\circ} \mathrm{C}$. was applied using the recent alcoholic modification of carmine by Snow (6), which gave satisfactory results. Stained anthers were dissected transversely in a drop of 45-percent acetic acid on an albuminized slide. Tapetum sacs with PMC were squeezed out, covered, heated gently, and squashed lightly. Proper stages were encountered in one single flowerbud $4 \mathrm{~mm}$. long and broad.

Photographic data were as follows: Ortholux microscope with 90:1 Phase Contrast objective and Makam camera (all Leitz); Kodak Ortho Contrast

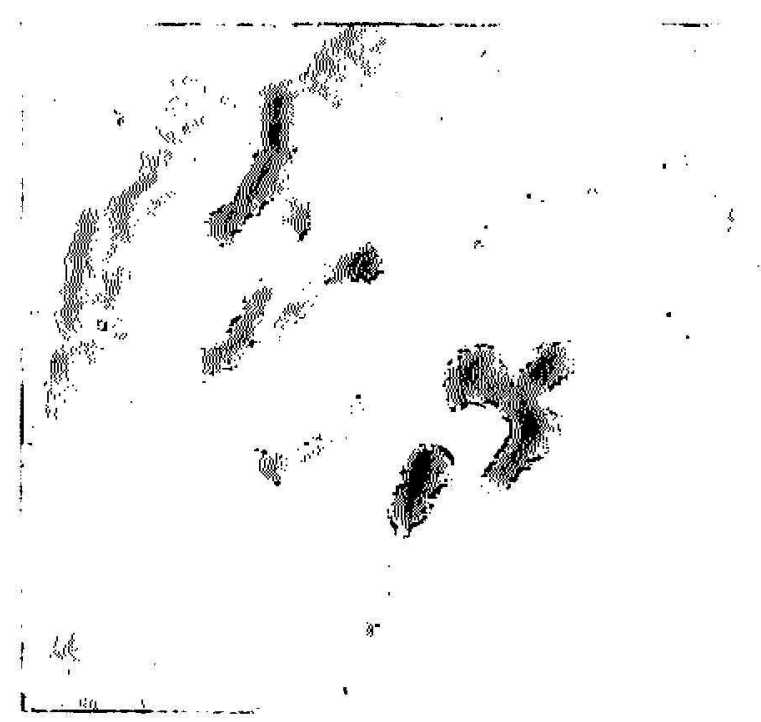

FIG. 1.-First meiotic metaphase of PMC in chironja, showing 9 bivalents.

P'rocess film and Kodabromide F-5 paper. Final magnification of photomicrographs is $2500 \times$.

\section{OBSERVATIONS}

A remarkable asynchrony in the proceeding of meiosis was noted in different anthers of the same flowerbud. Thirteen anthers were checked; of these one contained diplotene, two contained stages from diplotene to first metaphase, six contained first and second metaphase, one contained both metaphases and postmeiotic cell tetrads, and three contained cell tetrads only. A slight asynchrony was encountered also within anthers, the upper portion being more advanced than the lower.

From diakinesis on, the chromosomes are compact and stainable enough to be counted. There were nine bivalents. Most were cross- or rod-formed, but one or two rings might occur per nucleus. There were no markedly different members in the complement, but slight size differences could be noted.

The first meiotic metaphase (fig. 1) and anaphase (fig. 2) pass quite regu- 
larly. The only abnormal divisions seen were two second metaphases containing two plates with seven chromosomes, and one extra plate with three or four chromosomes. Such a situation has apparently arisen from the lagging of two chromosome pairs in the first anaphase, and a subsequent micronucleus formation. The form of the chromosomes in the second metaphase suggests metacentry.

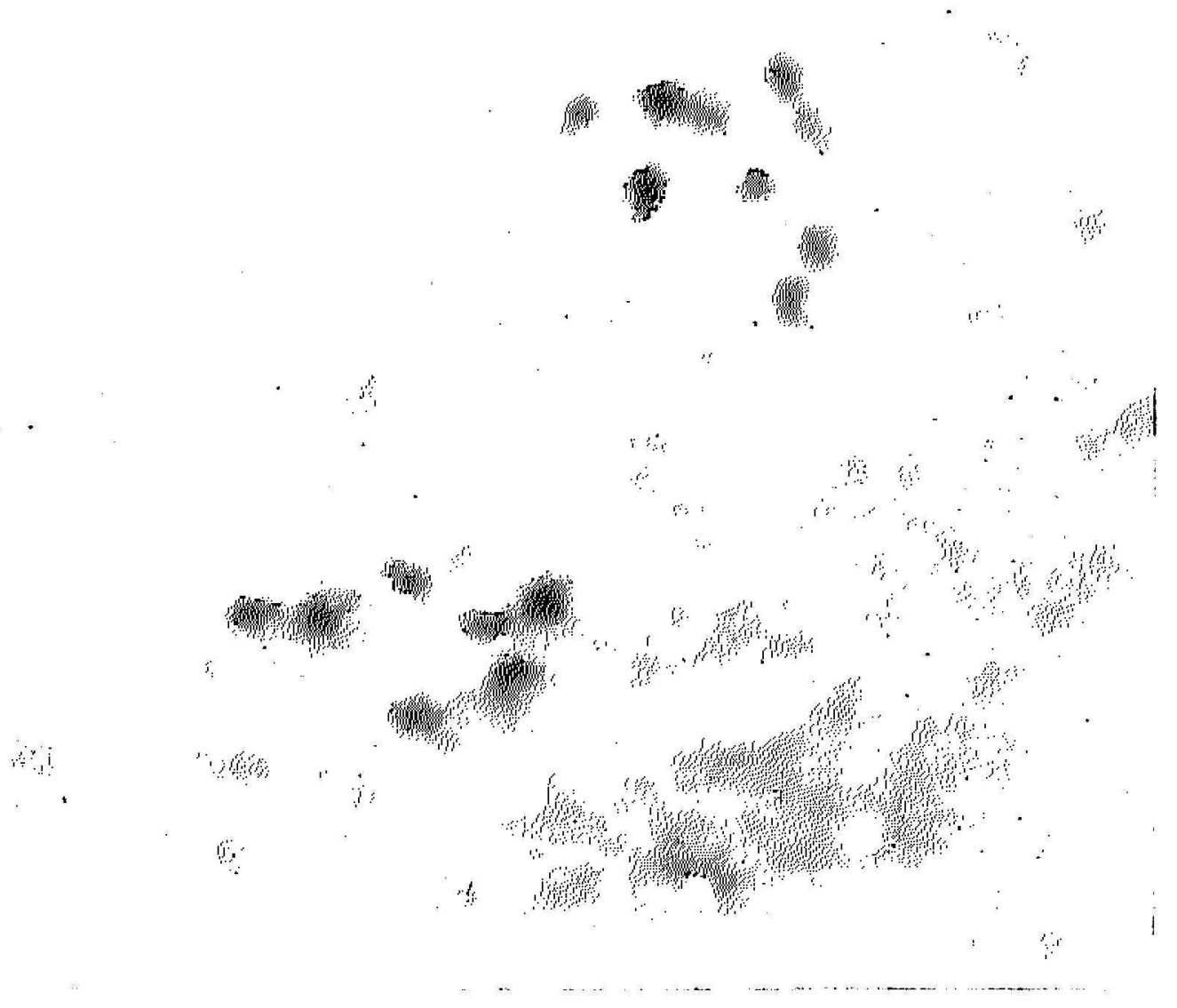

Fı,. 2.-First meiotic anaphase in chironja, showing 9 chromosomes (upper group).

Observations made on the size and starch content of pollen grains were in agreement with the above description of meiosis. All pollen grains werc stained with cotton blue. However, there were sporadic very small grains among the normal ones. This suggests that small separate micronuclei may sometimes develop up to tiny pollen.

\section{DISCUSSION}

The fact that chironja has the same chromosome number and form as most ('itrus diminishes the possibilities of discussing, on a cytological level, 
the question of the hybrid origin of this tree. Since the parent trees remain unknown it is not worthwhile to undertake the difficult and probably fruitless comparison of the fine longitudinal structure of the maternal and paternal homologues. Raghuvanshi (5) has observed that univalent formation is most common in Citrus varieties known, or supposed to be hybrids, and attributes this to structural differences. Multivalent formation in diploid varieties has been also encountered, owing, undoubtedly, to structural rearrangements (4). Because the PMC meiosis of chironja proceeds quite normally, no hint of the hybrid origin can be obtained from the chromosomal behavior either, though the possibility of hybrid origin need not be excluded.

Apomixis is common in Citrus. Although the embryo-sac development was not checked in chironja, the uniformity of its progeny obtained from seed (3) suggests that apomixis is involved. It is of importance for future breeding plans to know that the pollen of chironja is highly fertile, as estimated from the course of meiosis and the starch content of pollen.

\section{SUMMARY}

Like most Cilrus species and varieties, the Puerto Rican chironja has nine pairs of short chromosomes. Although micronuclei are formed sporadically, generally the P'MC meiosis is normal, and the pollen looks fertile. The chromosome relations do not help us to decide whether the chironja is a hybrid between orange and grapefruit or not.

\section{RESUMEN}

Igual que la mayoría de las especies y variedades de Citrus, la chironja puertorriqueña también tiene nueve pares de cromosomas cortos. Aunque se forman esporádicamente micronúcleos, generalmente la meiosis de CMP es normal y el polen parece fértil. Las relaciones cromosómicas no ayudan a determinar si la chironja es un híbrido entre la china y la toronja.

\section{LITERA'TURE CITED}

1. Darlington, C. D., and Wylie, A. P., Chromosome Atlas of Flowering Plants, pp. 519, Macmillan Co., New York, N. Y., 1956.

2. Krug, C., Chromosome numbers in the subfamily Aurantioidae with special reference to the genus (itrus, Bot. Gaz. 104 602-11, 1943.

3. Moscoso, C. G., The Puerto Rican chironja-new all-purpose citrus fruit, Econ. Bot. 12 87-94, 1958.

4. Naithani, S., and Raghuvanshi, S., Cytogenetical Studies in the (ienus Citrus, Nature 181 1406i-7, 1958.

5. Raghuvanshi, S., Cytogenetical studies in Genus ('itrus IV, Evolution in (ienus Citrus, C'ylologia 27 172-88, 1962.

6. Snow, R., Aleoholic hydrochloric acid-carmine as a stain for chromosomes in squash preparations, Stain T'erhn. 38 9-13, 1963. 